\title{
APICAL ROOT RESORPTION IN PATIENTS TREATED WITH EN-MASSE RETRACTION USING SKELETAL ANCHORAGE SYSTEM VERSUS CONVENTIONAL METHOD
}

\author{
Nahla Gomaa* and Shaimaa Elmarhoumy **
}

\begin{abstract}
Purpose: To compare external apical root resorption EARR in orthodontic patients treated with en-masse retraction with skeletal anchorage (miniscrews) versus two step procedures.

Patients and methods: Forty patients were randomly divided into two equal groups. Group I consisted of 20 patients were treated by using mini-screw anchorage and en-masse retraction, while, group II, 20 patients were treated with two-step retraction and conventional methods of anchorage reinforcement. Lateral cephalometric and digital panoramic radiographs were used to evaluate treatment changes just before (T1) and immediately after (T2) retraction of the maxillary anterior teeth.
\end{abstract}

Results: A significant positive correlation between age and root resorption. Shorter treatment duration was needed in group I with insignificant difference between both groups. Significant root resorption in maxillary central, lateral incisors, canines and first molars was found in both groups just after retraction. A significant root resorption was found for maxillary centrals and first molars in mini-implant group compared to conventional anchorage group. Upper first molars were intruded $(-1.8 \mathrm{~mm}, \mathrm{P}=0.041)$ in mini-implant group with no significant distalization $(\mathrm{P}=0.016)$ compared to conventional anchorage group. Upper incisors were significantly retracted $(-7.8 \mathrm{~mm}, \mathrm{P}=0.001)$ and intruded $(-2.3 \mathrm{~mm}, \mathrm{P}=0.017)$ in comparison to other group.

Conclusion: Skeletal anchorage system tends to permit more root resorption than conventional anchorage procedure. A significant retraction and intrusion of maxillary incisors, and a significant intrusion and lack of distalization of maxillary first molars by using skeletal anchorage system during en-masse retraction was found when compared with conventional anchorage procedure.

KEY WORDS: Apical root resorption ; en-masse retraction

* Assisstant professor of Orthodontics, Faculty of dentistry, Tanta University, Egypt.

** Lecturer of Orthodontics, Faculty of dentistry, Tanta University, Egypt. 


\section{INTRODUCTION}

External apical root resorption (EARR) is a common undesirable outcome of orthodontic treatment that may influence -in some cases- the results of effective treatment ${ }^{[1]}$.

Many factors can be related to root resorption during orthodontic treatment. Among these factors are the age, gender, type of malocclusion, root morphology, type of appliance, amount of force, duration of treatment and distance of teeth to be moved $^{[2,3,4]}$.

Regarding tooth movement type, intrusive force was considered as the most impeding to the root at times $^{[5]}$.

In contrast, many studies found no significant relationship between age and root resorption induced by orthodontic treatment ${ }^{[5,6,7]}$. Also, no significant relationship was observed between gender and root resorption in most researches ${ }^{[8]}$.

Root resorption occurs as a result of excessive orthodontic force that may lead to compression of cementoblast cells and periodontal blood vessels resulting in destruction of cementoblasts ${ }^{[9]}$.

Many studies found that maxillary incisors are the most teeth to be affected during orthodontic treatment in the form of apical root resorption. This ARR are most likely occurs in extraction cases ${ }^{[10,11]}$.

In premolar extraction cases, several methods can be used during space closure. The most common are two step and en masse retraction with sliding mechanics in straight wire technique ${ }^{[12]}$.

The need for implant technology was increased to reduce patient compliance demand and to maximize anchorage control. Miniscrews are considered superior to implants, onplants and miniplates because of their small size, simple surgical placement, no laboratory work was needed, very short waiting period, more indications, more sites to be implanted in, easily removed after treatment and low cost. Thus, they can be utilized as a part of many purposes: anterior teeth retraction; canine retraction, uprighting distalization and protraction of molars ${ }^{[13]}$.

The aim of this study was to compare external apical root resorption EARR in orthodontic patients treated with en masse retraction with skeletal anchorage (miniscrews) versus two step procedures. Additionally, the treatment effects on the maxillary incisors and maxillary molars were also quantified.

\section{PATIENTS AND METHODS}

Forty patients ( 6 males and 34 females) seeking orthodontic treatment in Orthodontic Department, Faculty of Dentistry, Tanta University were selected. Their selection was based on the following criteria: their age ranged from 18 to 24 years at the start of the treatment, orthodontic treatment plan required extraction of two maxillary first premolars and maximum anchorage permanent dentition, no canine impaction, no medical or dental contraindications for orthodontic treatment, no previous orthodontic treatment, no endodontically treated anteriors, and no history of trauma. Informed written consent was obtained after explaining the treatment procedure in detail to all patients.

All patients were treated with 0.022-inch bracket slot Roth appliances (Ormco. USA). After leveling and alignment, extraction space closure was achieved by using 0.017 X 0.025 -in stainless steel archwire. The patients were randomly divided into two groups. In group I, 20 patients were treated by using mini-screw anchorage and en-masse retraction. In group II, 20 were treated with two-step retraction and conventional methods of anchorage reinforcement such as; transpalatal arches, banding of the maxillary second molar, and multiple teeth at the anchorage segment.

The miniscrews were AbsoAnchor orthodontic microimplant anchor system (Dentos, Korea, $1.3 \mathrm{~mm}$ in diameter and $8 \mathrm{~mm}$ in length). They 
were implanted bilaterally between the maxillary second premolar and the first permanent molar using appropriate screwdriver. A force of 150$\mathrm{g}$ was applied immediately on each side with nickel-titanium closed coil spring extending from the implant to the crimpable hook for en-masse retraction of the maxillary anterior teeth (Fig.1).

Standardized lateral cephalometric and digital

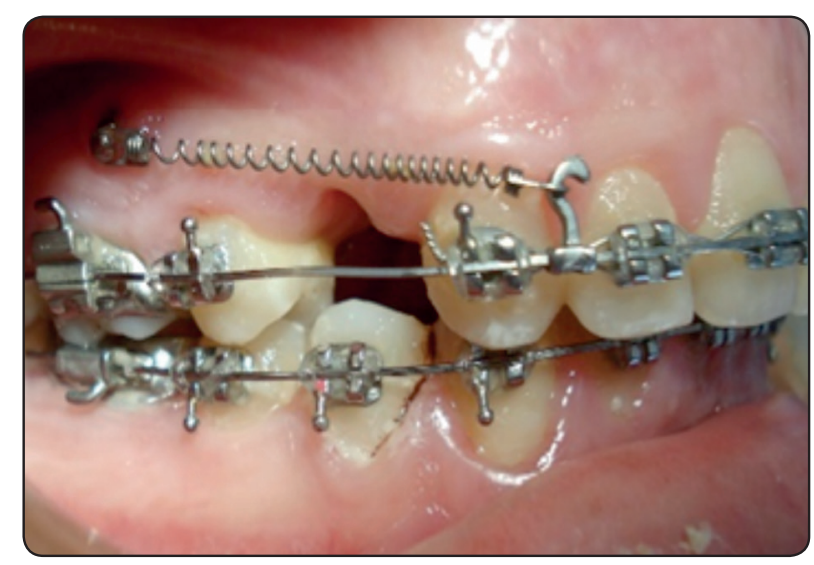

Fig (1): Force application with nickel-titanium closed coil spring.

panoramic radiographs were taken just before retraction of the maxillary anterior teeth (T1) and immediately after closure of the extraction space for the evaluation of the treatment changes (T2).

The cephalograms were traced with a $0.05-\mathrm{mm}$ lead pencil on an acetate tracing paper (Fig.2). Angular and linear measurements were made on each cephalometric radiograph for each subject to compare the treatment outcomes between the two groups. Horizontal and vertical positional changes of certain landmarks were measured in relation to a Cartesian coordinate system. A constructed Frankfort horizontal plane, drawn at an inferior angle of $7^{\circ}$ to SN plane through point "S" served as $\mathrm{X}$-axis and a line perpendicular to it through point "S" served as Y-axis.

The treatment changes for each cephalometric parameter were calculated by subtracting the measurements taken at $\mathrm{T} 1$ (pre-retraction) from

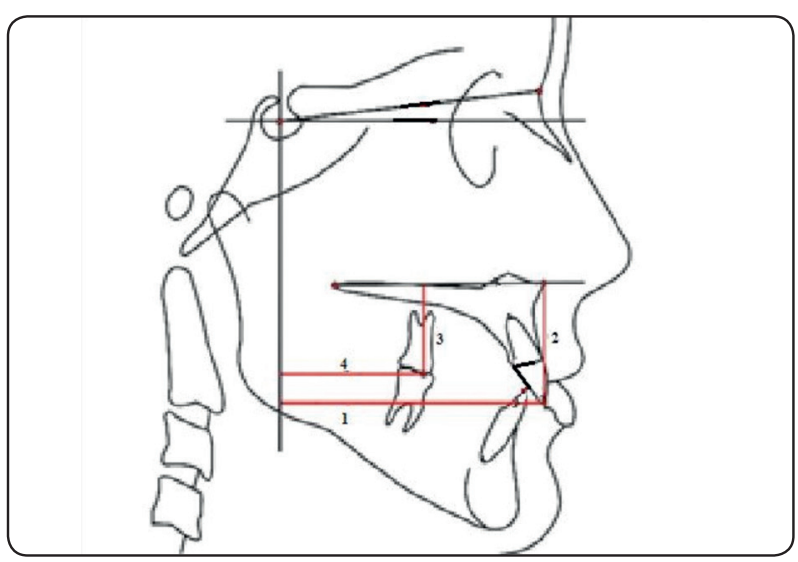

Fig (2): Dental measurement.

T2 (post-retraction) measurements. Linear measurements with a negative sign mean distal, backward, or intrusive movement to a relevant reference line, while a positive value indicates a forward, mesial, or extrusive movement. A positive value for a change in an angular measurement indicates that the measurement became more obtuse during treatment.

The radiographs were remeasured after a period of 2 weeks, and the readings of the first estimation were compared to the second one. A tolerance limit of $0.5 \mathrm{~mm}$ and $0.5^{\circ}$ was established for the difference between the first and second observations of linear and angular measurements respectively. If the limit was exceeded, a new tracing and measurements were made.

The roots of the maxillary incisors, canines, and upper first permanent molars were examined according to a modified root resorption classification method, based on the root resorption score (Sharpe et al., 1987). Panoramic radiographs were used to score the root resorption level for every patient at $\mathrm{T} 1$ and T2. The modified root resorption method is shown in Figure 3 and 4. The mean root resorption score (MRRS) for every patient at T1 and T2 was calculated for the upper anterior using the formula:

Reliability of measurement was determined by 


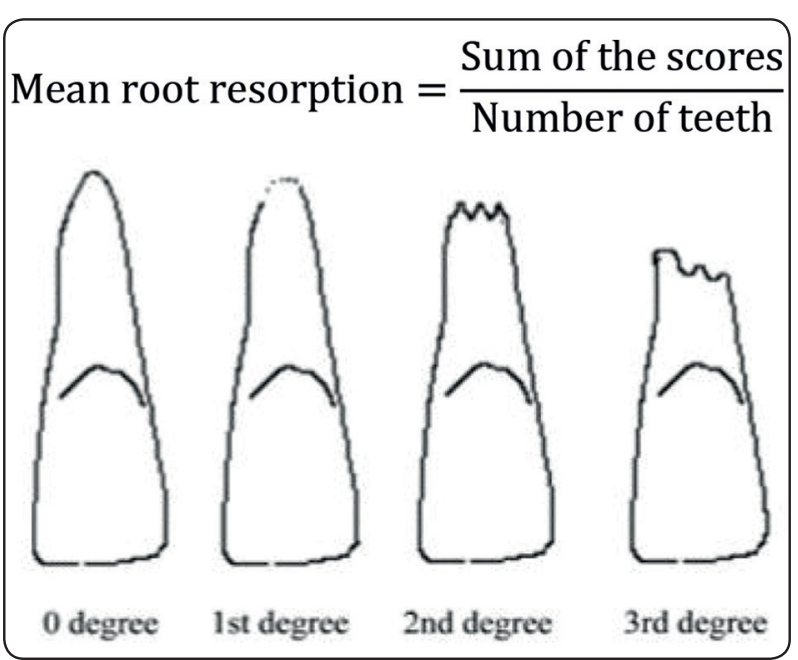

Fig (3): The modified root resorption classification method. 0 degree: no visible root resorption. 1st degree: mild resorption, the root apex is blunted and diffuse. 2nd degree: moderate resorption, the root apex disappears, the root apex looks more like a half circle not a taper. The contour is sometimes discontinuous or not smooth; the amount of root resorption is about approximately one-quarter of the root. 3rd degree: severe resorption, the end of the root shows excessive blunting; the contour of the root apex is more likely to be discontinuous; root resorption is more than one-quarter of the root.

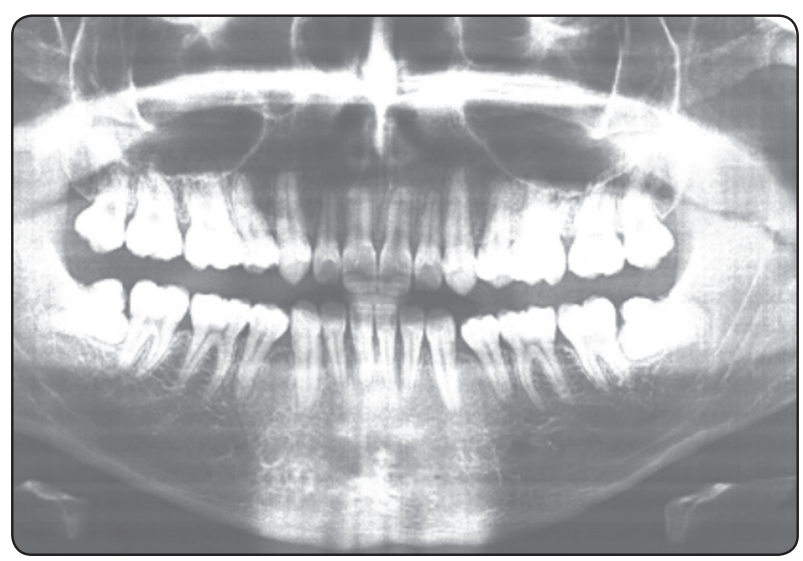

Fig (4): Grade 1: slight blunting of the root apex.

randomly selecting and re-checking by the same examiner 10 measurements 10 days after initial measurement. There was no significant difference between the first and second set of measurements by using Cronbach's alpha of reliability testing (Table 1).

\begin{tabular}{|c|c|c|c|c|c|}
\hline & $\begin{array}{c}\text { Scale Mean } \\
\text { if Item } \\
\text { Deleted }\end{array}$ & $\begin{array}{c}\text { Scale } \\
\text { Variance if } \\
\text { Item } \\
\text { Deleted }\end{array}$ & $\begin{array}{l}\text { Corrected } \\
\text { Item-Total } \\
\text { Correlation }\end{array}$ & $\begin{array}{c}\text { Squared } \\
\text { Multiple } \\
\text { Correlation }\end{array}$ & $\begin{array}{c}\text { Cronbach's } \\
\text { Alpha }\end{array}$ \\
\hline $\mathrm{A} 1$ & 0.5 & 0.5 & 0.899 & 0.808 & 0.947 \\
\hline A2 & 0.6 & 0.489 & 0.899 & 0.808 & \\
\hline B 1 & 0.9 & 0.989 & 0.954 & 0.91 & 0.976 \\
\hline B 2 & 1 & 1.111 & 0.954 & 0.91 & \\
\hline $\mathrm{Cl}$ & 0.4 & 0.267 & 1 & & 1.0 \\
\hline $\mathrm{C} 2$ & 0.4 & 0.267 & 1 & . & \\
\hline D 1 & 0.6 & 0.489 & 1 & & 1.0 \\
\hline D 2 & 0.6 & 0.489 & 1 & . & \\
\hline E 1 & 1.1 & 0.989 & 1 & . & 1.0 \\
\hline E2 & 1.1 & 0.989 & 1 & . & \\
\hline F 1 & 0.4 & 0.267 & 1 & . & 1.0 \\
\hline F2 & 0.4 & 0.267 & 1 & . & \\
\hline G 1 & & & & & \\
\hline G2 & & & & & \\
\hline $\mathrm{H} 1$ & 0.1 & 0.1 & 1 & . & 1.0 \\
\hline $\mathrm{H} 2$ & 0.1 & 0.1 & 1 & & \\
\hline
\end{tabular}

TABLE (1) Cronbach's alpha of reliability testing

\section{Statistical analysis:}

The collected data for the 40 patients was analyzed using SPSS software version 22. For assessment of treatment changes within the groups, a paired sample t. test was performed. The intergroup differences of the cephalometric measurements, duration of treatment, and apical root resorption were analyzed with Student $\mathrm{t}$ test. $\mathrm{P} \leq 0.05$ is considered statistically significant where $\mathrm{P} \leq 0.001$ is considered statistically highly significant.

\section{RESULTS}

Regarding age of the patients, an insignificant difference was found between both groups(Table 2). A positive correlation was found between age and root resorption in group I and group II (Table 3). 
TABLE (2) Mean age comparison between both groups:

\begin{tabular}{|c|c|c|c|c|}
\hline Age & Range & Mean \pm S. D & t. test & p. value \\
\hline G I & $18-22$ & $19.55 \pm 1.35$ & 0.016 & 0.899 \\
\cline { 1 - 3 } G II & $18-22$ & $19.60 \pm 1.12$ & & \\
\hline
\end{tabular}

The mean duration of retraction (months) for group 2 was longer than for group $1, t$ test analysis revealed an insignificant difference $(\mathrm{P}>0.05)$ between two groups (Table 4).

Amount of root resorption on maxillary central and lateral incisors, canines and first molars in group I is shown in Tables 5,6. A significant root resorption was found in all examined teeth after retraction.
TABLE (3) Correlation between age and root resorption:

\begin{tabular}{|c|c|c|c|c|}
\hline \multirow[t]{3}{*}{ With } & \multicolumn{4}{|l|}{ Age } \\
\hline & \multicolumn{2}{|l|}{ G IIa } & \multicolumn{2}{|c|}{ G IIb } \\
\hline & $\mathbf{r}$ & $\mathbf{P}$ & $\mathbf{r}$ & $\mathbf{P}$ \\
\hline Rt 1 & 0.622 & $0.003 *$ & 0.746 & 0.001* \\
\hline Rt 2 & 0.599 & $0.005^{*}$ & 0.688 & 0.001* \\
\hline Rt 3 & 0.809 & $0.001 *$ & 0.767 & 0.001* \\
\hline Rt6 MB & 0.743 & $0.001 *$ & 0.733 & 0.001* \\
\hline Rt 6 DB & 0.571 & $0.008^{*}$ & 0.527 & $0.017 *$ \\
\hline Lt 1 & 0.665 & $0.001 *$ & 0.954 & 0.001* \\
\hline Lt 2 & 0.743 & $0.001 *$ & 0.816 & 0.001* \\
\hline Lt 3 & 0.575 & $0.008^{*}$ & 0.767 & 0.001* \\
\hline Lt $6 \mathrm{MB}$ & 0.362 & 0.117 & 0.733 & 0.001* \\
\hline$L t 6 D B$ & 0.599 & $0.005^{*}$ & 0.740 & 0.001* \\
\hline
\end{tabular}

TABLE (4) Comparison of retraction duration (month) between mini-implant group (group I) and conventional anchorage group (group II).

\begin{tabular}{|l|c|c|c|c|c|}
\hline Retraction time & Mean & \pm & S. D & t. test & p. value \\
\cline { 1 - 3 } G I & 8.65 & \pm & 2.63 & 2.012 & 0.052 \\
\cline { 1 - 3 } G II & 10.37 & \pm & 2.78 & & \\
\hline
\end{tabular}

TABLE (5) Mean and standard deviation of root resorption of maxillary central and lateral incisors and canines in group I.

\begin{tabular}{|c|c|c|c|c|c|c|c|c|c|}
\hline \multicolumn{2}{|l|}{ G I } & \multicolumn{3}{|c|}{ Range } & \multirow{2}{*}{$\begin{array}{l}\text { Mean } \\
0\end{array}$} & \multirow[t]{2}{*}{ \pm} & \multirow{2}{*}{$\begin{array}{l}\text { S. D } \\
0.00 \\
\end{array}$} & \multirow{3}{*}{$\begin{array}{l}\text { t. test } \\
15.983\end{array}$} & \multirow{3}{*}{$\begin{array}{l}\text { p. value } \\
0.001^{*}\end{array}$} \\
\hline \multirow{2}{*}{$\begin{array}{l}\text { Upper right central incisor } \\
\text { (UR1) }\end{array}$} & Before & 0 & - & 0 & & & & & \\
\hline & After & 1 & - & 2 & 1.1 & \pm & 0.31 & & \\
\hline \multirow{2}{*}{$\begin{array}{l}\text { Upper right lateral incisor } \\
\text { (UR2) }\end{array}$} & Before & 0 & - & 0 & 0 & \pm & 0.00 & \multirow[t]{2}{*}{12.365} & \multirow[t]{2}{*}{$0.001 *$} \\
\hline & After & 1 & - & 2 & 1.3 & \pm & 0.47 & & \\
\hline \multirow{2}{*}{ Upper right canine (UR3) } & Before & 0 & - & 0 & 0 & \pm & 0.00 & \multirow[t]{2}{*}{5.339} & \multirow[t]{2}{*}{$0.001 *$} \\
\hline & After & 0 & - & 1 & 0.6 & \pm & 0.50 & & \\
\hline \multirow{2}{*}{$\begin{array}{l}\text { Upper left central incisor } \\
\text { (UR1) }\end{array}$} & Before & 0 & - & 1 & 0.1 & \pm & 0.31 & \multirow[t]{2}{*}{7.071} & \multirow[t]{2}{*}{$0.001 *$} \\
\hline & After & 0 & - & 2 & 1.1 & \pm & 0.55 & & \\
\hline \multirow{2}{*}{$\begin{array}{l}\text { Upper left lateral incisor } \\
\text { (UR2) }\end{array}$} & Before & 0 & - & 1 & 0.1 & \pm & 0.31 & \multirow[t]{2}{*}{9.590} & \multirow[t]{2}{*}{$0.001^{*}$} \\
\hline & After & 1 & - & 2 & 1.2 & \pm & 0.41 & & \\
\hline \multirow[t]{2}{*}{ Upper left canine (UR3) } & Before & 0 & - & 0 & 0 & \pm & 0.00 & \multirow[t]{2}{*}{5.339} & \multirow[t]{2}{*}{$0.001 *$} \\
\hline & After & 0 & - & 1 & 0.6 & \pm & 0.50 & & \\
\hline
\end{tabular}

$* P<0.05$ denotes significant. 
Tables 7,8 show amount of root resorption on maxillary central and lateral incisors, canines and first molars in group II. Amount of root shortening after retraction was significant compared to that before retraction.

Comparison between two groups regarding EARR revealed a non-significant difference for all examined teeth except for upper central incisor and upper first molars. They were significantly shortened in group I than in group II (Table 9,10 ).

Table 11,12 and 13 showed treatment changes in the incisor position (U1-Sv) in G I showed - $7.800 \pm$ $2.486 \mathrm{~mm}$ while in G II was $-5.50 \pm 1.96 \mathrm{~mm}$. The difference was statistically significant in the amount of incisor retraction between the two groups $(\mathrm{P}<$ 0.05). As regard to the vertical movement of the maxillary central incisors (U1 - PP), statistically significant amount of intrusion of the upper incisors were recorded in G I (- $2.300 \pm 1.059 \mathrm{~mm})$ while, they were significantly extruded in G II ( $3.10 \pm 1.19$ $\mathrm{mm}$ ). The changes in molar position during retraction obtained from the cephalometric radiographs were $-1.800 \pm 0.919 \mathrm{~mm}(\mathrm{U} 6-\mathrm{PP})$ and $-2.55 \pm 1.257 \mathrm{~mm}$ (U6-Sv) for G I, and $1.95 \pm 0.49 \mathrm{~mm}(\mathrm{U} 6-\mathrm{PP}$ ) and $3.20 \pm 1.23 \mathrm{~mm}$ (U6-Sv) in G II. The differences were highly significant between the two groups $(\mathrm{P}$ $<0.001)$.

TABLE (6) Mean and standard deviation of root resorption of maxillary right and left first molars in group I.

\begin{tabular}{|c|c|c|c|c|c|c|c|c|c|}
\hline \multicolumn{2}{|c|}{ G I } & \multicolumn{3}{|c|}{ Range } & \multirow{2}{*}{$\begin{array}{c}\text { Mean } \\
0.10 \\
\end{array}$} & \multirow{2}{*}{$\begin{array}{l} \pm \\
\pm\end{array}$} & \multirow{2}{*}{$\begin{array}{l}\text { S. D } \\
0.31 \\
\end{array}$} & \multirow{3}{*}{$\begin{array}{c}\text { t. test } \\
14.394\end{array}$} & \multirow{2}{*}{$\begin{array}{c}\text { p. value } \\
0.001^{*}\end{array}$} \\
\hline \multirow[t]{2}{*}{ Right 6 MB } & Before & 0 & - & 1 & & & & & \\
\hline & After & 0 & - & 1 & 0.60 & \pm & 0.50 & & \\
\hline \multirow[t]{2}{*}{ Right 6 DB } & Before & 0 & - & 1 & 0.20 & \pm & 0.41 & \multirow[t]{2}{*}{16.540} & \multirow[t]{2}{*}{$0.001 *$} \\
\hline & After & 0 & - & 1 & 0.75 & \pm & 0.44 & & \\
\hline \multirow[t]{2}{*}{ Left $6 \mathrm{MB}$} & Before & 0 & - & 1 & 0.10 & \pm & 0.31 & \multirow[t]{2}{*}{18.102} & \multirow[t]{2}{*}{$0.001 *$} \\
\hline & After & 0 & - & 1 & 0.65 & \pm & 0.49 & & \\
\hline \multirow[t]{2}{*}{ Left 6 DB } & Before & 0 & - & 1 & 0.10 & \pm & 0.31 & \multirow[t]{2}{*}{18.102} & \multirow[t]{2}{*}{$0.001 *$} \\
\hline & After & 0 & - & 1 & 0.65 & \pm & 0.49 & & \\
\hline
\end{tabular}

$* P<0.05$ denotes significant.

TABLE (7) Mean and standard deviation of root resorption of maxillary central and lateral incisors and canines in group II.

\begin{tabular}{|c|c|c|c|c|c|c|c|c|c|}
\hline \multicolumn{2}{|l|}{ G II } & \multicolumn{3}{|c|}{ Range } & Mean & \pm & S.D & t. test & p. value \\
\hline \multirow{2}{*}{$\begin{array}{l}\text { Upper right central } \\
\text { incisor (UR1) }\end{array}$} & Before & 0 & - & 0 & 0 & \pm & 0.00 & \multirow[t]{2}{*}{3.943} & \multirow[t]{2}{*}{$0.001 *$} \\
\hline & After & 0 & - & 2 & 0.6 & \pm & 0.68 & & \\
\hline \multirow{2}{*}{$\begin{array}{c}\text { Upper right lateral incisor } \\
\text { (UR2) }\end{array}$} & Before & 0 & - & 0 & 0 & \pm & 0.00 & \multirow[t]{2}{*}{4.359} & \multirow[t]{2}{*}{$0.001 *$} \\
\hline & After & 0 & - & 2 & 1 & \pm & 1.03 & & \\
\hline \multirow[t]{2}{*}{ Upper right canine (UR3) } & Before & 0 & - & 0 & 0 & \pm & 0.00 & \multirow[t]{2}{*}{3.559} & \multirow[t]{2}{*}{$0.001 *$} \\
\hline & After & 0 & - & 1 & 0.4 & \pm & 0.50 & & \\
\hline \multirow{2}{*}{$\begin{array}{c}\text { Upper left central incisor } \\
\text { (UR1) }\end{array}$} & Before & 0 & - & 0 & 0 & \pm & 0.00 & \multirow[t]{2}{*}{3.943} & \multirow[t]{2}{*}{$0.001 *$} \\
\hline & After & 0 & - & 2 & 0.6 & \pm & 0.68 & & \\
\hline \multirow{2}{*}{$\begin{array}{c}\text { Upper left lateral incisor } \\
\text { (UR2) }\end{array}$} & Before & 0 & - & 0 & 0 & \pm & 0.00 & \multirow[t]{2}{*}{5.082} & \multirow[t]{2}{*}{$0.001 *$} \\
\hline & After & 0 & - & 2 & 1.1 & \pm & 0.97 & & \\
\hline \multirow[t]{2}{*}{ Upper left canine (UR3) } & Before & 0 & - & 0 & 0 & \pm & 0.00 & \multirow[t]{2}{*}{3.559} & \multirow[t]{2}{*}{$0.001 *$} \\
\hline & After & 0 & - & 1 & 0.4 & \pm & 0.50 & & \\
\hline
\end{tabular}

$* P<0.05$ denotes significant. 
TABLE (8) Mean and standard deviation of root resorption of maxillary right and left first molars in group II.

\begin{tabular}{|c|c|c|c|c|c|c|c|c|c|}
\hline \multicolumn{2}{|c|}{ G II } & \multicolumn{3}{|c|}{ Range } & Mean & \pm & S. D & t. test & p. value \\
\hline \multirow[t]{2}{*}{ Right 6 MB } & Before & 0 & - & 1 & 0.10 & \pm & 0.31 & \multirow[t]{2}{*}{3.740} & \multirow[t]{2}{*}{$0.042 *$} \\
\hline & After & 0 & - & 1 & 0.35 & \pm & 0.49 & & \\
\hline \multirow[t]{2}{*}{ Right 6 DB } & Before & 0 & - & 1 & 0.15 & \pm & 0.37 & \multirow[t]{2}{*}{3.231} & \multirow[t]{2}{*}{$0.047 *$} \\
\hline & After & 0 & - & 1 & 0.40 & \pm & 0.50 & & \\
\hline \multirow[t]{2}{*}{ Left $6 \mathrm{MB}$} & Before & 0 & - & 1 & 0.05 & \pm & 0.22 & \multirow[t]{2}{*}{4.612} & \multirow[t]{2}{*}{$0.038 *$} \\
\hline & After & 0 & - & 1 & 0.30 & \pm & 0.47 & & \\
\hline \multirow[t]{2}{*}{ Left 6 DB } & Before & 0 & - & 1 & 0.10 & \pm & 0.31 & \multirow[t]{2}{*}{3.740} & \multirow[t]{2}{*}{$0.042 *$} \\
\hline & After & 0 & - & 1 & 0.35 & \pm & 0.49 & & \\
\hline
\end{tabular}

${ }^{*} P<0.05$ denotes significant.

TABLE (9) Comparison between two groups in root resorption in upper centrals, laterals and canines.

\begin{tabular}{|c|c|c|c|c|c|c|c|c|c|}
\hline \multicolumn{2}{|l|}{ After } & \multicolumn{3}{|c|}{ Range } & \multirow{2}{*}{\begin{tabular}{c|} 
Mean \\
1.1
\end{tabular}} & \multirow{2}{*}{$\begin{array}{l} \pm \\
\pm\end{array}$} & \multirow{2}{*}{$\begin{array}{l}\text { S. D } \\
0.31 \\
\end{array}$} & \multirow{3}{*}{2.994} & \multirow{3}{*}{$\begin{array}{l}\text { p. value } \\
0.005^{*}\end{array}$} \\
\hline \multirow{2}{*}{$\begin{array}{c}\text { Upper right central incisor } \\
\text { (UR1) }\end{array}$} & G I & 1 & - & 2 & & & & & \\
\hline & G II & 0 & - & 2 & 0.6 & \pm & 0.68 & & \\
\hline \multirow{2}{*}{$\begin{array}{c}\text { Upper right lateral incisor } \\
\text { (UR2) }\end{array}$} & G I & 1 & - & 2 & 1.3 & \pm & 0.47 & \multirow[t]{2}{*}{1.189} & \multirow[t]{2}{*}{0.242} \\
\hline & G II & 0 & - & 2 & 1 & \pm & 1.03 & & \\
\hline \multirow[t]{2}{*}{ Upper right canine (UR3) } & G I & 0 & - & 1 & 0.6 & \pm & 0.50 & \multirow[t]{2}{*}{1.258} & \multirow[t]{2}{*}{0.216} \\
\hline & G II & 0 & - & 1 & 0.4 & \pm & 0.50 & & \\
\hline \multirow{2}{*}{$\begin{array}{l}\text { Upper left central incisor } \\
\text { (UR1) }\end{array}$} & G I & 0 & - & 2 & 1.1 & \pm & 0.55 & \multirow[t]{2}{*}{2.551} & \multirow[t]{2}{*}{$0.015^{*}$} \\
\hline & G II & 0 & - & 2 & 0.6 & \pm & 0.68 & & \\
\hline \multirow{2}{*}{$\begin{array}{c}\text { Upper left lateral incisor } \\
\text { (UR2) }\end{array}$} & G I & 1 & - & 2 & 1.2 & \pm & 0.41 & \multirow[t]{2}{*}{0.425} & \multirow[t]{2}{*}{0.673} \\
\hline & G II & 0 & - & 2 & 1.1 & \pm & 0.97 & & \\
\hline \multirow[t]{2}{*}{ Upper left canine (UR3) } & G I & 0 & - & 1 & 0.6 & \pm & 0.50 & \multirow[t]{2}{*}{1.258} & \multirow[t]{2}{*}{0.216} \\
\hline & G II & 0 & - & 1 & 0.4 & \pm & 0.50 & & \\
\hline
\end{tabular}

$* P<0.05$ denotes significant.

TABLE (10) Comparison between two groups in root resorption in upper first molars.

\begin{tabular}{|c|c|c|c|c|c|c|c|c|c|}
\hline \multicolumn{2}{|l|}{ After } & \multicolumn{3}{|c|}{ Range } & \multirow{2}{*}{$\begin{array}{c}\text { Mean } \\
0.60 \\
\end{array}$} & \multirow{2}{*}{$\begin{array}{l} \pm \\
\pm\end{array}$} & \multirow{2}{*}{$\begin{array}{l}\text { S. D } \\
0.50 \\
\end{array}$} & \multirow{3}{*}{$\begin{array}{l}\text { t. test } \\
3.852\end{array}$} & \multirow{3}{*}{$\begin{array}{c}\text { p. value } \\
0.040^{*}\end{array}$} \\
\hline \multirow[t]{2}{*}{ Right 6 MB } & G I & 0 & - & 1 & & & & & \\
\hline & G II & 0 & - & 1 & 0.35 & \pm & 0.49 & & \\
\hline \multirow[t]{2}{*}{ Right 6 DB } & G I & 0 & - & 1 & 0.75 & \pm & 0.44 & \multirow[t]{2}{*}{5.443} & \multirow[t]{2}{*}{$0.025 *$} \\
\hline & G II & 0 & - & 1 & 0.40 & \pm & 0.50 & & \\
\hline \multirow[t]{2}{*}{ Left $6 \mathrm{MB}$} & G I & 0 & - & 1 & 0.65 & \pm & 0.49 & \multirow[t]{2}{*}{5.320} & \multirow[t]{2}{*}{$0.027 *$} \\
\hline & G II & 0 & - & 1 & 0.30 & \pm & 0.47 & & \\
\hline \multirow[t]{2}{*}{ Left 6 DB } & G I & 0 & - & 1 & 0.65 & \pm & 0.49 & \multirow[t]{2}{*}{3.785} & \multirow[t]{2}{*}{$0.041 *$} \\
\hline & G II & 0 & - & 1 & 0.35 & \pm & 0.49 & & \\
\hline
\end{tabular}

$* P<0.05$ denotes significant. 
TABLE (12) Changes in the cephalometric variables in group II.

\begin{tabular}{|c|c|c|c|c|c|}
\hline G II & Before & After & Difference & t. test & p. value \\
\hline U $\mathbf{1}-\mathbf{S v} \mathbf{~ m m}$ & $79.80 \pm 4.44$ & $74.30 \pm 4.32$ & $-5.50 \pm 1.96$ & 3.972 & $\mathbf{0 . 0 0 1} *$ \\
\hline U $\mathbf{1}-\mathbf{P P} \mathbf{~ m m}$ & $27.40 \pm 3.37$ & $30.50 \pm 4.25$ & $3.10 \pm 1.19$ & 2.563 & $\mathbf{0 . 0 1 5} *$ \\
\hline $\mathbf{U} \mathbf{6}-\mathbf{P P} \mathbf{~ m m}$ & $23.65 \pm 2.33$ & $25.60 \pm 2.32$ & $1.95 \pm 0.49$ & 2.652 & $\mathbf{0 . 0 1 2} *$ \\
\hline $\mathbf{U} \mathbf{6}-\mathbf{S v} \mathbf{~ m m}$ & $\mathbf{3 9 . 3 0} \pm \mathbf{4 . 9 0}$ & $\mathbf{4 1 . 5 0} \pm \mathbf{4 . 7 3}$ & $\mathbf{3 . 2 0} \pm \mathbf{1 . 2 3}$ & $\mathbf{2 . 1 0 2}$ & $\mathbf{0 . 0 4 2} *$ \\
\hline
\end{tabular}

$* P<0.05$ denotes significant

TABLE (13) Comparison of the cephalometric variables between the two groups.

\begin{tabular}{|c|c|c|c|c|}
\hline Dental measurements & G I & G II & t. test & p. value \\
\hline U $\mathbf{1}-\mathbf{S v} \mathbf{~ m m}$ & $-7.800 \pm 2.486$ & $-5.50 \pm 1.96$ & 3.253 & $\mathbf{0 . 0 0 3} *$ \\
\hline $\mathbf{U} \mathbf{1}-\mathbf{P P} \mathbf{~ m m}$ & $-2.300 \pm 1.059$ & $3.10 \pm 1.19$ & 10.072 & $\mathbf{0 . 0 0 1} *$ \\
\hline $\mathbf{U} \mathbf{6}-\mathbf{P P} \mathbf{~ m m}$ & $-1.800 \pm 0.919$ & $1.95 \pm 0.49$ & 7.483 & $\mathbf{0 . 0 0 1} *$ \\
\hline $\mathbf{U} \mathbf{6}-\mathbf{S v} \mathbf{~ m m}$ & $\mathbf{- 2 . 5 5} \pm \mathbf{1 . 2 5 7}$ & $\mathbf{3 . 2 0} \pm \mathbf{1 . 2 3}$ & $\mathbf{9 . 9 8 2}$ & $\mathbf{0 . 0 0 1}$ \\
\hline
\end{tabular}

$* P<0.05$ denotes significant.

\section{DISCUSSION}

This study aimed to compare EARR in orthodontic patients treated with en masse retraction with skeletal anchorage (miniscrews) versus two step procedures and to evaluate the efficacy of skeletal anchorage for en-masse retraction of maxillary anterior teeth and compare them with conventional methods of anchorage reinforcement.

EARR can be assessed using lateral cephalometric, panoramic or periapical x-rays. It was found that owing to crowding especially in incisors, localization of root apices is difficult. Also, root resorption mostly ocuur at root apex in $1-2 \mathrm{~mm}$ which is a small area to be measured by lateral cephalometric $\mathrm{x}$-ray ${ }^{[15]}$.Panorama has an advantage of being only a single film that give information about teeth, dentoalveolar bone and jaw. But, distortion of teeth that may occur is considered a limitation of using panoramic x-ray. As periapical $\mathrm{x}$-ray is considered as an accurate method, the amount of x-ray exposure is high and changes of incisor tipping -during treatmentmake difficult periodic identical periapical x-ray ${ }^{[16]}$. Thus, panoramic film was used in this work by using ordinal scale instead of measuring root length directly from x-ray. Ordinal scale method is used to overcome magnification of teeth in panoramic film. It depends on change of root apex shape not the root length ${ }^{[5,17]}$.

In the current study, 40 patients indicated for extraction of maxillary first premolars and maximum retraction of anterior teeth were randomly divided into two equal groups. In group I, mini-implant was used for en-masse retraction of maxillary anterior teeth with sliding mechanics. While, in group II, two step retraction method was performed with anchorage reinforcement by conventional methods.

Mini-implant used in the present work was $1.3 \mathrm{~mm}$ diameter and $8 \mathrm{~mm}$ long to increase mechanical retention and avoid any possible contact 
between the root that may lead to failure during retraction $^{[18,19,20]}$.

They were placed at $30-60^{\circ}$ to maxillary arch bone surface so the apices of mini-implant are away from the roots. Site of implantation incisoapically was at the mucogingival junction. This site eliminate the need to mucoperiosteal flap reflection or mucosal incision ${ }^{[21,22,23]}$.

The site of insertion of mini-implant was between maxillary second premolars and first molars. This site gives good accessibility, easier maintenance of oral hygiene and good retention ${ }^{[24]}$.

Nickel-titanium closed coil spring with light force was used immediately after placement of mini-implant for retraction as it provides constant force over a wide range, effective tooth movement and mini-implant stability ${ }^{[25]}$.

Elastomerics were not used as a mean of retraction because they give an excessive initial force and they deformed permanently when exposed to oral environment due to absorption of saliva and water leading to stress relaxation of elastomerics[25].A power arm was placed on an archwire between the lateral incisor and canine to maintain better control of the anterior teeth during retraction ${ }^{(26)}$.

In en-masse group; precalibrated nickel-titanium closed coil springs (150-200gms/side) were used to be within the physiologic limit. So, the applied force was considered light to overcome or decrease EARR caused by heavy force, and equally distribute forces along the root surface without concentration on one point, especially during en-masse retraction ${ }^{[26,27]}$.

In the current study, stainless steel rectangular rigid archwires $(0.017 \mathrm{X} 0.025 \mathrm{inch})$ in 0.022 inch bracket slot were used as they give faster tooth movement due to less friction than $0.019 \quad 0.025$. This result was in agreement with Basha et al; $2010^{[28]}$.

Regarding age of the patients, a significant difference was found between age and root resorption . This finding coincided with those of Jiang et al; 2010, who found a positive correlation between age and root resorption. This means that root resorption was increased in older patients ${ }^{[1]}$. In contrast, Sameshima and Sinclair stated that a nonsignificant difference was found between age and root resorption ${ }^{[29]}$.

Results of the current study revealed that maxillary incisors and first molars showed EARR in both groups but it was significantlly greater in group I than in group II. These results were in accordance with many authors whom all found that maxillary incisors are more susceptible to EARR during orthodontic treatment ${ }^{[4,7,8,29]}$. This resorption may be attributed to that in extraction cases larger tooth movement was needed to correct teeth position and maloclussion leading to more apical displacement and resorption.

Topkara et al; ${ }^{[30]}$; were in accordance with these results. They stated that maxillary incisors were the mostly affected teeth by orthodontic forces followed by first molars.

The probable explanation for lesser resorption of maxillary incisors in group II than in group I may be that, during two step retraction, roots of incisors are subjected to less force during retraction of canine that tends to cause less root resorption of incisors.

Barroos et al; agreed with results of this work in that greater root resorption was obtained in miniimplant group, but they found an insignificant difference with the other group as they compared degree of maxillary central incisor root resorption by retraction with and without skeletal anchorage. They concluded that root resorption was high in mini-implant group in relation to conventional anchorage group ${ }^{[31]}$.

In contrast, Liou and Chang stated that, maxillary incisors were more prone to root resorption during orthodontic treatment without using miniscrews as an anchorage, ${ }^{[32]}$. 
Significant differences were found also between pre and post treatment results in canine resorption in both groups with insignificant difference between them.

Agarwal et al; ${ }^{[33]}$ studied effect of extraction and non extraction on EARR on anterior teeth represented by maxillary and mandibular canines, and on posterior teeth represented by premolars and molars. They demonstrated a significant root resorption in extraction compared to non extraction cases. As the current study was done in extraction cases, results obtained by Agarwal et al; were in agreement with present results.

Mini-implant group showed less duration for space closure than group II, but without a significant difference between them. Similar result was obtained by Upadhyay et al; and Basha et al; ${ }^{[21,28]}$. A possible explanation can be attributed to that, space closure in mini-implant group was carried out only by distalization of incisors and canines, while in the other group, anterior and posterior teeth were moved simultaneously to close extraction space leading to anchorage loss ${ }^{[29,34]}$.

On the other hand, other studies found a significant difference between en-masse retraction of upper canines and incisors with skeletal anchorage system and retraction by conventional two steps procedure ${ }^{[35,36]}$.

Linear measurement (U1-Sv) was used to assess the amount of retraction of upper anterior teeth. Results revealed that the amount of retraction was greater in in GI $(-7.8 \mathrm{~mm})$ than in GII $(-5.5 \mathrm{~mm})$. This finding was in accordance with Park et al., 2012 ,Al-Sibaie and Hajeer, 2014 and Lee et al., $2013^{[35,36,37]}$ whom all stated that distal movement of upper incisors was greater in mini-implant group than those of conventional anchorage group. This supports the concept indicates that an anchorage control of anteroposterior molar position changes is better obtained by using mini-implants than conventional anchorage procedure. All these findings can explain the increased EARR of maxillary incisors in mini-implant group than in conventional anchorage group.

In contrast, a non significant difference was found between mini-implant and conventional anchorage mechanics regarding incisor retraction in a study done by Feldmann et al; ${ }^{[38]}$.

Regarding maxillary incisors intrusion, a statistically significant intrusion level was found in mini-implant group $(-2.3+1.05 \mathrm{~mm})$, but, a small amount of extrusion was observed in group II using conventional anchorage mechanics $(+3.10+1.19$ $\mathrm{mm})$. This observation was in agreement with AlSibaie and Hajeer, 2014, Upadhyay et al., 2009 , Kim et al., $2011^{[36,39,40]}$.

On the other hand, Park et al; ${ }^{[41]}$ found an insignificant change in maxillary central incisors vertical measurements during retraction of maxillary anterior teeth using titanium screws and conventional anchorage mechanics.

Anterior teeth intrusion caused by using miniimplant as skeletal anchorage device can be attributed to that nickel-titanium coil springs had two distinct components of force: a retractive force which is large and predominant and a vertical small intrusive force, giving an en-masse retraction and some intrusion of the anterior teeth. So, the force of retraction can be directed by changing vertical height of the crimpable hook ${ }^{[42,43]}$. This can explain the significant increase in root resorption in miniimplant group in the current study compared to conventional anchrage group.

On the other hand, extrusion of upper incisors was reported by Araujo et al; $2012^{[44]}$ during enmasse retraction of the upper anterior teeth using mini-implant as an anchorange. This can be attributed to that the applied retraction force from the titanium screws to hooks with long arm soldered on the archwire was parallel to the occlusal plane. 
In the current study, a significant difference was found in anteroposterior movements of the upper first molars between both groups. Mini-implants were considered as ankylosd teeth giving absolute anchorage and distal movement $(-2.55+1.26 \mathrm{~mm})$ of the upper first molars in mini-implant group, while, upper first molars showed mesial movement $(3.20+1.23 \mathrm{~mm})$ in conventional anchorage group.

In mini-implant group, upper first molars were intruded, while, extrusion of upper first molars was observed in conventional anchorage group. Thus, root resorption of upper first molar was significantly high in mini-implant group compared to conventional anchorage group. Same results were found in clinical cephalometric studies using en-masse retraction of maxillary anterior teeth and micro-implant anchorage ${ }^{[45,46,47]}$.

Many studies were done on upper first molars movement during en-masse retraction using miniimplant anchorage. These studies revealed stability of upper first molars movement vertically and horizontally ${ }^{[18,46,48,49,50]}$. Others revealed distal first molar movement in mini-implant anchorage group. This may be due to that the continuation of the retraction force after space closure between canine and second premolar was transmitted to posterior segments through the interdental contacts ${ }^{[34,39,45,51]}$. On the other hand, mesial movement of upper molars even during using mini-implant anchorage procedure was reported by some studies. This can be attributed to the using of utility archwires during retraction without engaging the upper molars supported by mini-implants during treatment ${ }^{[52]}$, delayed initiation of the retraction after early extraction of the upper first premolars at the beginning of the treatment leading to physiological mesial movement of upper molars ${ }^{[49,53,54)]}$ and difference in the retraction mechanics used ${ }^{[55]}$.

In conventional anchorage group, a significant anchorage loss represented by mesial migration of upper molars was found. This concept was in line with those found by Kocadereli and Kim et a ${ }^{[56,57]}$.

\section{CONCLUSION}

- Age found to be positively correlated to EARR

- No significant difference was found in duration of treatment between both groups although duration of treatment was longer in two step group.

- All maxillary incisors and first molars in this study showed EARR during retraction of maxillary anterior teeth either by en-masse or two step procedure.

- EARR was more significant in maxillary centrals and first molars in mini-implant group compared to conventional anchorage group.

- Mini-implant allows for retraction and intrusion of maxillary incisors while, two step procedure allows lesser amount of retraction and extrusion.

- Mini-implant allows intrusion and distal movement of maxillary first molars while, two step procedure may results in significant amounts of anchorage loss vertically and horizontally.

\section{REFERENCES}

1. Jiang RP, McDonald JP, Fu M. Root resorption before and after orthodontic treatment: a clinical study of contributory factors. Eur J Ortho, 2010; 32:693-7.

2. Baumrind S, Korn E L, Boyd R L. Apical root resorption in orthodontically treated adults. Am J Orthod Dentofacial Orthop. 1996; $110: 311-23$.

3. Jiang RP, Zhang D, Fu M K. A clinical study of root resorption before and after orthodontic treatment. Chinese Journal of Orthodontics. 2001;8: 108-10.

4. Apajalahti S and Peltola J S. Apical root resorption after orthodontic treatment- a retrospective study. Eur J Ortho, 2007;29: 408-12.

5. Beck B W, Harris E F. Apical root resorption in orthodontically treated subjects. Am J Orthod Dentofacial Orthop. 1994; 105 : 350-61.

6. Owman M P, Kurol J. The early reparative process of orthodonticallly induced root resorption in adolescentsocation and type of tissue. Eur J Ortho, 1998; 20:727-32. 
7. Mavragani M, Vergari A, Selliseth N J, Boe O E, Wissth $\mathrm{P}$ J. A radiographic comparison of apical root resorption after orthodontic treatment with a standard edgewise and straight wire edgewise technique. Eur J Ortho, 2000; 22:665-74.

8. Kjaer I. Morphological characteristics of dentitions developing excessive root resorption during orthodontic treatment. Eur J Ortho, 1995; 17:25-34.

9. Diercke K, Kohl A, Lux C J, Erber R. Compression of human primary cementoblasts leads to apoptosis; a possible cause of dental root resorption?. J Orofac Orthop. 2014;75:430-45.

10. Janson GR, De Luca Canto G, Martins DR, Hentiques JF, De Freitas MR. A radiographic comparison of apical root resorption after orthodontic treatment with 3 different fixed appliance techniques. Am J Orthod Dentofacial Orthop. 2000; $118: 262-73$.

11. McNab S, Battistutta D, Taverne A, Symons AL. External root resorption following orthodontic treatment. Angle Orthod .2000;70:227-32.

12. Proffit WR, Fields HW. Cntemporary Orthodontics. $3^{\text {rd }}$ ed. St Louis, MO: Mosby; 1999.

13. Eric JW, Liou and Chang MH. Apical root resorption in orthodontic patients with en-masse maxillary anterior retraction and intrusion with miniscrews. Am J Orthod Dentofacial Orthop. 2010; 137 :207-12.

14. Sharpe W, Reed B, Subtelny JD, Polson A. Orthodontic relapse, apical root resorption and crestal alveolar bone levels. Am J Orthod Dentofacial Orthop. 1987; 91 :252-58.

15. Kennedy D B, Joondeph D R, Osterberg S K, Little R M. The effect of extractions and orthodontic treatment on dentoalveolar support. Am J Orthod Dentofacial Orthop. 1983; 84 :183-91.

16. Levander E, Bajka R, Malmgren O. early radiographic diagnosis of apical root resorption during orthodontic treatment: a study of maxillary incisors. European Journal of Orthodontics, 1998; 20:57-63.

17. Sharpe W, Reed B, Subtelny JD, Poison A. orthodontic relapse, apical root resorption and crestal alveolar bone levels. Am J Orthod Dentofacial Orthop. 1987; 91 :252-8.

18. Park HS, Kwon OW, Sung JH: Microscrew implant anchorage sliding mechanics. World J Orthod. 2005; 6:265-74.
19. Kuroda S, Sugawara Y, Deguchi T, Kyung HM, Takano-Yamamoto T: Clinical use of miniscrew implants as orthodontic anchorage: success rates and postoperative discomfort. Am J Orthod Dentofacial Orthop. 2007; 131: 9-15.

20. Kaku M, Kojima S, Sumib H, Kosekib H, Abedinib S, Motokawaa M, Fujitaa T, Ohtania J, Kawatac T, Tanned $\mathrm{K}$ : Gummy smile and facial profile correction using miniscrew anchorage. Angle Orthod. 2012; 82: 170-77.

21. Upadhyay M, Yadav S: Mini-implants for retraction, intrusion and protraction in a class II division 1 patient. $\mathrm{J}$ Orthod. 2007; 34:158-67.

22. Baumgaertel S, Razavi MR, Hans MG: Mini-implant anchorage for the orthodontic practitioner. Am J Orthod Dentofacial Orthop. 2008; 133:621- 27.

23. Laursen MG, Melsen B, Cattaneo PM: An evaluation of insertion sites for mini-implants. A micro-CT study of human autopsy material. Angle Orthod. 2013; 83: 222-29.

24. Schnelle MA, Beck FM, Jaynes RM, Huga SS: A radiologic evaluation of the availability of bone for placement of mini-screws. Angle Orthod. 2004; 74:832-37.

25. Kyung HM, Park HS, Bae SM, Kwon OW, Sung JH: Development of orthodontic micro-implant (AbsoAnchor). Brochure for the AbsoAnchor orthodontic micro-implant. 2008; 6 th ed.

26. Tominaga J, Tanaka M, Koga Y, Gonzales C, Kobayashi M, Yoshida N: Optimal loading conditions for controlled movement of anterior teeth in sliding mechanics. A 3D finite element study. Angle Orthod. 2009; 79: 1102- 7.

27. Barbagallo LJ, Jones AS, Petocs P, Darendeliler MA. Physical properties of root cementum: part 10. Comparison of the effects of invisible removable thermoplastic appliances with light and heavy orthodontic forces on premolar cementum. A microcomputed tomography study. Am J Orthod Dentofacial Orthop. 2008; 133 :218-27.

28. Basha AG, Shantaraj R, Mogegowda SB. Comparative study between conventional en-masse retraction (sliding mechanics)and en-masse retraction using orthodontic microimplant. Implant Dent. 2010; 19:128-36.

29. Sameshima G T, Sinclair P M. Prediction and prevention root resorption Part 1: diagnostic factors. Am J Orthod Dentofacial Orthop. 2001a; $119: 505-10$.

30. Topkara A, Karaman A, Kau C. apical root resorption caused by orthodontic forces: A brief review and a long term observation. Eur J Dent. 2012;6:445-53. 
31. Sameshima G T, Sinclair P M. Prediction and prevention root resorption Part 2: treatment factors. Am J Orthod Dentofacial Orthop. 2001b; $119: 511-15$.

32. Liou J W, Chang M H.Apical root resorption in orthodontic patients with en-masse maxillary anterior retraction and intrusion with miniscrews. Am J Orthod Dentofacial Orthop. 2010; $137: 207-12$.

33. AgarwelS S, Chopra S S, Komar C, Jayan B, Nehra K, Sharma M. A radiographic study of external apical root resorption in patients treated with single-phase fixed orthodontic therapy. Medical J Armed Forces India. 2016 s8-s16.

34. Upadhyay M, Yadav S, Nagaraj K, Patil S: Treatment effects of mini-implants for en-masse retraction of anterior teeth in bialveolar dental protrusion patients: A randomized controlled trial. Am J Orthod Dentofacial Orthop. 2008; 134: 18-29.

35. Park HM, Kim BH, Yang HI, Baek SH: Preliminary three-dimensional analysis of tooth movement and arch dimension change of the maxillary dentition in Class II division 1 malocclusion treated with first premolar extraction: conventional anchorage vs mini-implant anchorage. Korean J Orthod. 2012; 42:280-90.

36. Al-Sibaie S, Hajeer MY: Randomized controlled trial. Assessment of changes following en-masse retraction with mini-implants anchorage compared to two-step retraction with conventional anchorage in patients with class II division 1 malocclusion: a randomized controlled trial. Eur J Orthod. 2014; 36: 275-83.

37. Lee J, Miyazawa K, Tabuchi M, Kawaguchi M, Shibata M, Goto S: Midpalatal miniscrews and high-pull headgear for anteroposterior and vertical anchorage control: Cephalometric comparisons of treatment changes. Am J Orthod Dentofacial Orthop. 2013; 144: 238-50.

38. Feldmann I, Bondemark L: Anchorage capacity of osseointegrated and conventional anchorage systems: a randomized controlled trial. Am J Orthod Dentofacial Orthop. 2008; 133: 339.e19-339.e28.

39. Upadhyay M, Yadav S, Nagaraj K, Nanda R: Dentoskeletal and soft tissue effects of mini-implants in class II division 1 patients. Angle Orthod. 2009; 79:240-47.

40. Kim JS, Kim SH, Kook YA, Chung KR, Nelson G: Analysis of lingual en-masse retraction combining a C-lingual retractor and a palatal plate. Angle Orthod. 2011, 81: 662-69.
41. Park HS, Yoon DY, Park CS, Jeoung SH: Treatment effects and anchorage potential of sliding mechanics with titanium screws compared with the Tweed-Merrifield technique. Am J Orthod Dentofacial Orthop. 2008; 133: 593-600.

42. Ma J, Wang L, Zhang W, Chen W, Zhao C, Smales R: Comparative evaluation of micro-implant and headgear anchorage used with a pre-adjusted appliance system. Eur J Orthod. 2008; 30: 283-87.

43. Upadhyay M, Yadav S, Nanda R: Vertical-dimension control during en-masse retraction with mini-implant anchorage. Am J Orthod Dentofacial Orthop. 2010; 138: 96-108.

44. Araújo LH, Zenóbio EG, Pacheco W, Cosso MG, Manzi FR, Shibli JA: Mass retraction movement of the anterior upper teeth using orthodontic mini-implants as anchorage. Oral Maxillofac Surg. 2012; 16: 95-9.

45. Upadhyay M, Yadav S, Patil S: Mini-implant anchorage for en-masse retraction of maxillary anterior teeth: A clinical cephalometric study. Am J Orthod Dentofacial Orthop. 2008; 134:803 -10.

46. Koyama I, Iino S, Abe Y, Yamamoto T, Miyawaki S: Differences between sliding mechanics with implant anchorage and straight-pull headgear and intermaxillary elastics in adults with bimaxillary protrusion. Eur J Orthod. 2011; 33: 126-31.

47. Yao CJ, Lai EH, Chang JZ, Chen I, Chen YJ: Comparison of treatment outcomes between skeletal anchorage and extraoral anchorage in adults with maxillary dentoalveolar protrusion. Am J Orthod Dentofacial Orthop. 2008; 134: 615-24.

48. Aljhani A, Zawawi KH: The use of mini-implants in enmasse retraction for the treatment of bimaxillary dentoalveolar protrusion. Saudi Dental Journal. 2010; 22: 35-39.

49. Chung KR, Nelson G, Kim SH, and Kook YA: Severe bidentoalveolar protrusion treated with orthodontic microimplant-dependent en-masse retraction. Am J Orthod Dentofacial Orthop. 2007; 132: 105-15.

50. Park YC, Choi YJ, Choi NC, Lee JS: Esthetic segmental retraction of maxillary anterior teeth with a palatal appliance and orthodontic mini-implants. Am J Orthod Dentofacial Orthop. 2007; 131: 537-44.

51. Nagaraj K, Upadhyay M, Yadav S: Mini-implant anchorage for a skeletal class II malocclusion with missing mandibular incisors: A case report. World J Orthod. 2008; 9:155-66. 
52. Kim SH, Hwang YS, Ferreira A, Chung KR: Analysis of temporary skeletal anchorage devices used for en-masse retraction: A preliminary study. Am J Orthod Dentofacial Orthop. 2009; 136: 268-76.

53. Park HS, Kwon TG: Sliding mechanics with microscrew implant anchorage. Angle Orthod. 2004; 74: 703-10.

54. Yao CJ, Lai EH, Chang JZ, Chen I, Chen YJ: Comparison of treatment outcomes between skeletal anchorage and extraoral anchorage in adults with maxillary dentoalveolar protrusion. Am J Orthod Dentofacial Orthop. 2008; 134: 615-24.
55. Lee J, Miyazawa K, Tabuchi M, Kawaguchi M, Shibata M, Goto S: Midpalatal miniscrews and high-pull headgear for anteroposterior and vertical anchorage control: Cephalometric comparisons of treatment changes. Am J Orthod Dentofacial Orthop. 2013; 144: 238-50.

56. Kocadereli I: The effect of first premolar extraction on vertical dimension. Am J Orthod Dentofacial Orthop. $1999 ; 116: 41-5$.

57. Kim TK, Kim JT, Mah J, Yang WS, Baek SH: First or second premolar extraction effects on facial vertical dimension. Angle Orthod. 2005; 75:177-82. 